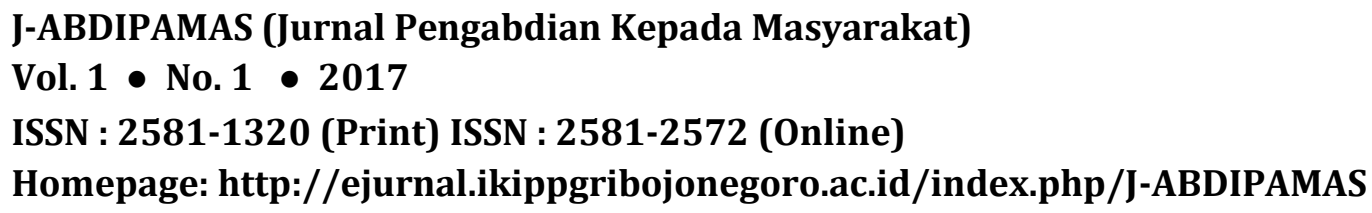

ISSN : 2581-1320 (Print) ISSN : 2581-2572 (Online)

Homepage: http://ejurnal.ikippgribojonegoro.ac.id/index.php/J-ABDIPAMAS

\title{
DAUR ULANG BOTOL BEKAS MENJADI PIGGY BANKS UNTUK MENGASAH KREATIVITAS DAN MEMOTIVASI SISWA UNTUK MENABUNG
}

\author{
Siti Ermawati ${ }^{1}$, Taufiq Hidayat ${ }^{2}$, Fitri Nurdianingsih ${ }^{3}$, Ima Isnaini Taufiqur Rohmah ${ }^{4}$, \\ Ali Mujahidin ${ }^{5}$ \\ ${ }^{1}$ IKIP PGRI Bojonegoro. Email: ermawati.saja2016@gmail.com \\ ${ }^{2}$ IKIP PGRI Bojonegoro. Email: hyadayat_taufiq27@yahoo.com \\ ${ }^{3}$ IKIP PGRI Bojonegoro. Email: fitriafip12@gmail.com \\ ${ }^{4}$ IKIP PGRI Bojonegoro. Email: rimataufiq83@gmail.com \\ ${ }^{5}$ IKIP PGRI Bojonegoro. Email: ali.mujahidin17@gmail.com
}

\begin{abstract}
The rubbish is the waste of goods that are not needed by the community. However, it does not mean that rubbish does not have any utility at all. Actually, used bottles can be recycled into a variety of creative products. Unfortunately, just a few people are willing to exploit the potential of the rubbish, so its existence becomes useless, and even just pollute the environment. This community service program aims to hone the creativity of students in recycling the bottles into unique piggy banks and improving students' movements to save their money. The method used in this program is Participatory Rural Appraisal (PRA). The participants are the students of class 5 SDN Prigi 1 $(n=14)$. The steps of program implementation include; 1) counseling, 2) demonstration, 3) tools provision, 4) practice, and 5) evaluation. The results of the program are the partisipant's understanding and skill in recycling the bottles into unique and creative piggy banks. Some piggy bank products produced by participants include; a turtle-shaped pig, an owl, and a plane. Students are expected to be more motivated to save their from an early age.
\end{abstract}

Keywords: Recycle, Used bottles, Piggy banks

\begin{abstract}
ABSTRAK
Sampah merupakan sisa atau buangan dari barang yang tidak diperlukan oleh masyarakat. Meskipun demikian, bukan berarti sampah tidak memiliki kegunaan sama sekali. Botol bekas sebenarnya bisa didaur menjadi berbagai produk kreatif yang memiliki nilai guna dan nilai ekonomi. Persoalannya, sangat sedikit orang dapat mememanfaatkan potensi sampah sehingga keberadaannya menjadi sia-sia dan bahkan menjadi limbah yang mencemari lingkungan. PKM ini bertujuan untuk mengasah kreativitas siswa dalam mendaur ulang botol bekas menjadi Piggy Banks dan meningkatkan movitasi siswa untuk menabung. Metode yang digunakan dalam kegiatan PKM ini adalah Participatory Rural Appraisal (PRA). Peserta PKM terdiri dari siswa Kelas V SDN Prigi 1 yang berjumlah 14 Orang. Langkah-langkah pelaksanaan PKM meliputi; 1) penyuluhan, 2) demonstrasi, 3) pemberian bantuan alat, 4) praktek, dan 5) evaluasi. Hasil dari kegiatan PKM ini adalah pemahaman dan keterampilan siswa dalam mendaur ulang botol bekas menjadi piggy bank unik dan kreatif. Beberapa produk piggy bank yang dihasilkan siswa antara lain; piggy bank berbentuk kura-kura, burung hantu, dan pesawat. Dengan hasil ini, siswa diharapkan dapat lebih termotivasi untuk menabung sejak usia dini.
\end{abstract}

Kata Kunci: Daur ulang, Botol bekas, Piggy banks 


\section{PENDAHULUAN}

Salah satu persoalan lingkungan yang sampai saat ini masih menjadi pekerjaan rumah bagi masyarakat adalah sampah. Pencemaran lingkungan akibat sampah semakin lama akan semakin mengkhawatirkan apabila tidak ada usaha yang efektif untuk mengatasinya. Pencemaran akibat sampah bukan saja terhadap tanah, tapi juga terhadap udara dan air (Bagus, 2002).

Menurut UU No.18 Tahun 2008, sampah adalah sisa kegiatan sehari-hari manusia dan/atau proses alam yang berbentuk padat. Sampah dapat dibagi menjadi dua bentuk yaitu; organik dan anorganik. Sampah organik adalah sampah yang terbentuk dari zatzat organik dan dapat diuraikan, contohnya daun. Sedangkan sampah anorganik adalah sampah yang berasal dari benda-benda yang tidak dapat diuraikan, contohnya adalah botol, kaleng, dan plastik bekas makanan atau minuman.

Meskipun sampah merupakan sisa atau buangan dari barang yang tidak diperlukan oleh masyarakat, ini bukan berarti sampah tidak memiliki kegunaan sama sekali. Sisa-sisa dedaunan, misalnya, dapat dimanfaatkan oleh masyarakat sebagai kompos (pupuk organik) untuk menyuburkan tanah. Contoh lain, adalah botol bekas, kaleng bekas, dan plastik bekas yang kelihatannya sudah tidak berguna, sebenarnya dapat didaur ulang dan dijadikan berbagai jenis produk yang memiliki nilai guna dan ekonomi.

Botol dan kaleng bekas minuman merupakan salah satu jenis sampah yang banyak ditemui. Namun sangat sedikit orang yang dapat memanfaatkan barang-barang ini, tak terkecuali masyarakat di Desa Prigi. Pada akhirnya barang-barang tersebut menjadi sia-sia dan bahkan menjadi limbah yang mencemari lingkungan.

Sebenarnya botol bekas dapat didaur ulang menjadi barang kreatif dan berguna. Botol bekas dapat dijadikan mainan anak-anak, vas bunga, wadah tanaman hias, bahkan dapat juga dijadikan piggy bank sederhana.

Minimnya pemanfaatan sampah anorganik salah satunya disebabkan oleh ketidaktahuan masyarakat dalam mengolah atau mendaur ulang sampah tersebut. Oleh sebab itu, kegiatan yang bersifat edukasi terkait bagaimana cara memanfaatkan botol bekas menjadi produk yang kreatif dirasa perlu dilakukan. Kegiatan pengabdian kepada masyarakat ini bertujuan untuk mengasah kreativitas siswa dalam mendaur ulang botol bekas menjadi piggy bank unik dan meningkatkan movitasi siswa untuk menabung.

\section{METODE PELAKSANAAN}

Kegiatan Pengabdian kepada Masyarakat (PKM) ini dilakukan kepada mitra, yaitu siswa kelas V SDN Prigi di Kecamatan Kanor Kabupaten Bojonegoro. Metode yang digunakan dalam kegiatan PKM ini adalah Participatory Rural Appraisal (PRA) atau pendekatan partisipatif dalam pengembangan masyarakat. Menurut Chambers (dalam Sumbodo, dkk, 2017), PRA adalah suatu pendekatan dan metode untuk mempelajari kondisi dan kehidupan pedesaan dari, dengan, dan oleh masyarakat desa.

Kegiatan pengabdian kepada masyarakat ini dilaksanakan dengan beberapa tahapan yaitu; 1) penyuluhan, 2) demonstrasi, 3) pemberian bantuan alat, 4) praktik, dan 5) evaluasi. Pada tahap pertama, tim pelaksana PKM memberikan penyuluhan 
kepada peserta tentang potensi pendayagunaan botol bekas dan pentingnya menabung sejak dini.

Pada tahap kedua, tim pelaksana PKM mendemontrasikan tips mendaur ulang botol bekas menjadi piggy bank sederhana dan unik dengan mengenalkan kepada peserta alat dan bahan yang digunakan serta cara membuat piggy bank dengan botol bekas. Tahap ketiga, tim pelaksana PKM memberikan bantuan berupa alat, perlengkapan, dan bahan-bahan yang dibutuhkan dalam proses pembuatan piggy bank, seperti gunting, penggaris, kain flanel, dan kertas buffalo agar pengetahuan yang telah ditransfer kepada peserta dapat langsung dipraktekkan.

Tahap keempat, tim pelaksana PKM memberikan kesempatan bagi peserta untuk memperaktekkan pengetahuan yang telah diperoleh tentang pembuatan piggy bank unik dan kreatif dengan bahan dasar botol bekas. Pada saat praktik, tim pelaksana PKM memberikan pendampingan kepada peserta. Hal ini dilakukan untuk membantu peserta apabila di dalam kegiatan tersebut menemui kendala dan hambatan. Tujuan utama dari pendampingan ini adalah memberikan solusi atas setiap masalah yang tidak dapat dipecahkan oleh peserta.

Pada tahap kelima, tim pelaksana PKM melakukan evaluasi hasil kegiatan dengan menilai proses kerja mitra, kualitas produk yang dihasilkan, serta komentar mitra terhadap kegiatan ini. Evaluasi ini dimaksudkan untuk mengetahui sejauh mana keberhasilan kegiatan PKM, dan sekaligus untuk mengetahui kelayakannya untuk tetap diimplementasikan secara konsisten oleh mitra setelah mengikuti kegiatan PKM.

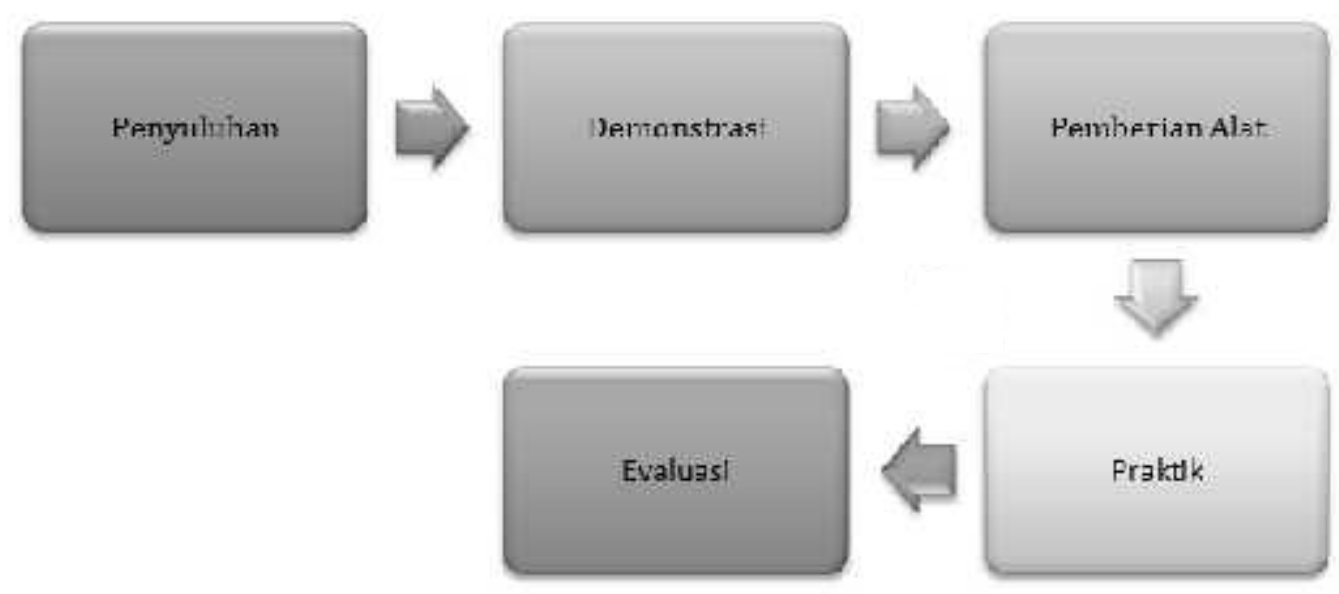

\section{Gambar 1. Tahapan Pelaksanaan PKM}

\section{HASIL DAN PEMBAHASAN}

\section{Penyuluhan dan Demonstrasi}

Kegiatan penyuluhan dan demonstrasi dilaksanakan pada hari selasa, tanggal 12 september 2017 bertempat di SDN Prigi 1, Desa Prigi, Kecamatan Kanor, Kabupaten Bojonegoro. Kegiatan ini diikuti oleh 14 peserta yaitu siswa kelas V SDN Prigi 1.

Penyuluhan berisi pemaparan materi tentang potensi pendayagunaan botol bekas dan pentingnya menabung sejak dini. Pada segmen ini, pelaksana PKM berfokus pada pembahasan mengenai; 1) manfaat mendaur ulang sampah botol bekas, 2) 
berbagai jenis produk yang dapat dihasilkan dengan mendaur ulang sampah botol bekas, 3) manfaat menabung sejak dini bagi masa depan, dan 4) cara menabung secara konsisten.

Sedangkan demonstrasi berisi tentang teknik pembuatan piggy bank kreatif dari botol bekas. Pada tahapan ini, pelaksana PKM memberikan contoh proses pembuatan piggy bank berbentuk kura-kura, burung hantu, dan pesawat. Dimulai dari pengenalan alat dan bahan yang diperlukan, sampai kemudian memberikan contoh pembuatan piggy bank secara langsung.

Kegiatan penyuluhan dan demonstrasi berjalan dengan lancar. Peserta PKM tidak hanya pasif menyimak materi dan demonstrasi, melainkan juga aktif bertanya kepada pelaksana PKM mengenai hal-hal yang belum dimengerti. Peserta menunjukkan rasa ingin tahu yang besar, terlihat dari keseriusan dan pro aktif mereka pada saat kegiatan penyuluhan dan demonstrasi berlangsung.

Di akhir kegiatan, tim pelaksana PKM meminta para peserta untuk mencari botol bekas minuman yang ada di sekitar rumah mereka dan membawa botol bekas tersebut ke kelas pada hari berikutnya. Botol bekas tersebut kemudian dijadikan bahan pembuatan piggy bank kreatif pada kegiatan praktek pada hari Rabu, 13 September 2017.

\section{Praktek Pembuatan Piggy Banks}

Kegiatan praktek pembuatan piggy bank kreatif dilakukan pada hari Rabu, 13 September 2017. Kegiatan ini kembali diikuti oleh 14 peserta. Selanjutnya peserta dibagi menjadi 4 kelompok dan setiap kelompok terdiri dari 3-4 orang.

Dalam praktek ini, setiap kelompok diberikan kesempatan untuk mengembangkan idenya setelah mendapatkan materi (penyuluhan dan demonstrasi). Selama kegiatan berlangsung, masing-masing kelompok membuat piggy bank kreatif dari botol bekas dalam bentuk Burung Hantu, Kura-Kura, atau Pesawat. Sedangkan pelaksana PKM mendampingi peserta dalam proses pembuatan piggy bank kreatif.

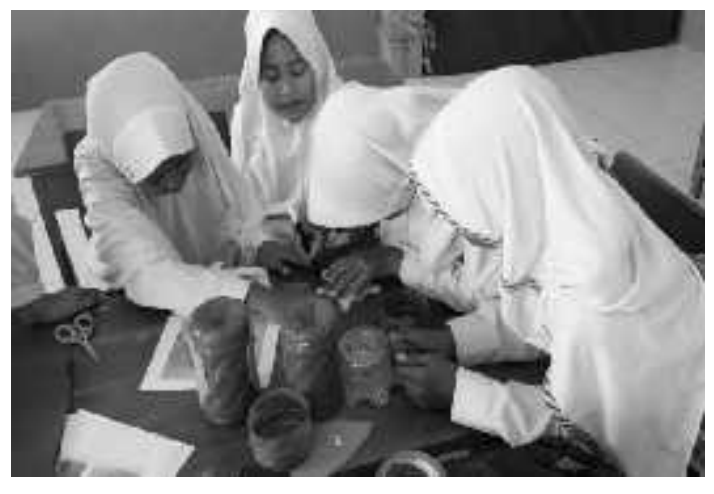

Gambar 2. Salah Satu Kelompok Peserta PKM sedang Membuat Piggy Bank Burung Hantu

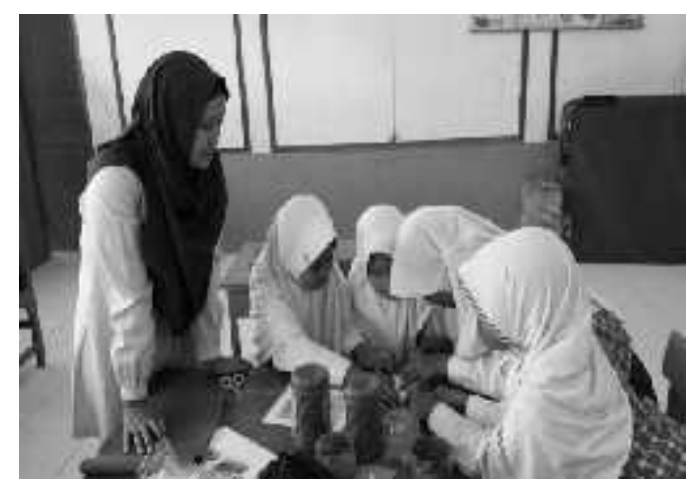

Gambar 3. Pelaksana PKM Mendampingi Kelompok dalam Kegiatan Praktik

Kegiatan praktek ini berlangsung lancar dan para peserta terlihat lebih antusias saat diberikan kesempatan memperaktekkan langsung pengolahan botol bekas menjadi piggy bank kreatif. Respon peserta cenderung positif, mereka terlihat senang mengikuti 
kegiatan. Jumlah peserta yang mengikuti kegiatan pada saat praktek juga tidak berkurang daripada hari sebelumnya.

Pembuatan piggy bank kreatif dengan cara berkelompok ternyata memiliki banyak manfaat. Selain proses pembuatan piggy bank menjadi lebih cepat, di setiap kelompok juga terjalin kerjasama dan saling tukar pikiran, sehingga menghasilkan piggy bank yang menarik.

Salah satu kendala yang terjadi selama berlangsungnya kegiatan ini adalah ada sebagian kelompok yang masih bingung dengan langkah-langkah pembuatan piggy bank, meskipun pada hari sebelumnya telah diberikan contoh pembuatannya oleh tim pelaksana PKM. Namun setelah diberikan pengarahan, kegiatan dapat dilanjutkan karena peserta sudah memahami langkah-langkah dan teknik pembuatan piggy bank.

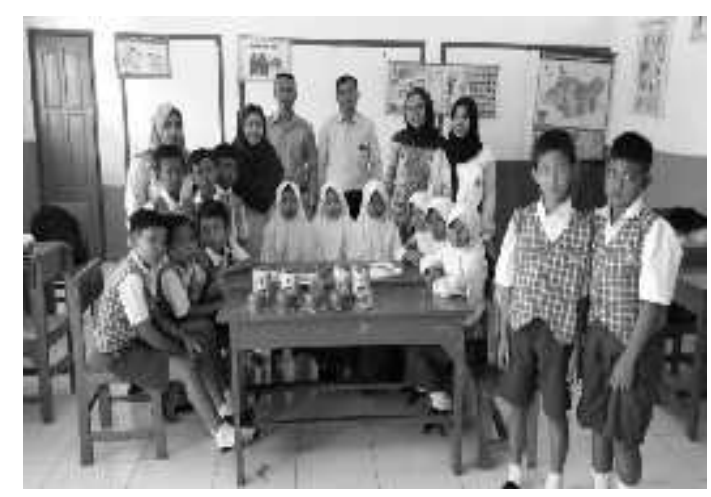

Gambar 3. Pelaksana dan Peserta PKM

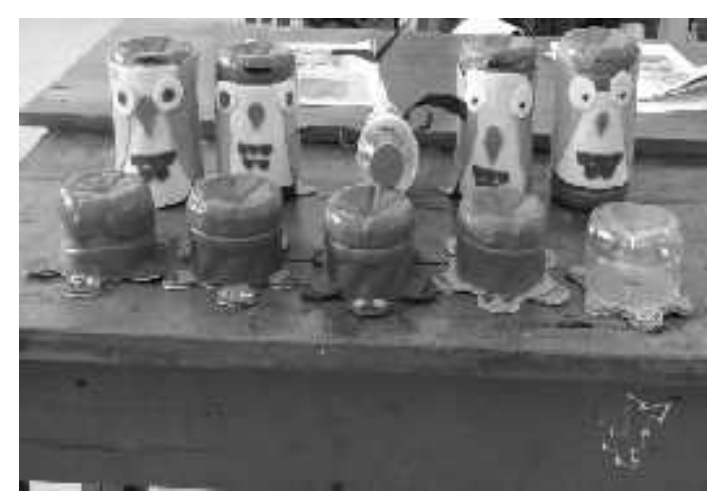

Gambar 4. Piggy Bank Hasil Kreasi Peserta PKM

Pada akhir kegiatan, semua kelompok berhasil membuat karya piggy bank kreatif berbahan dasar botol bekas minuman. Kelompok 1, kelompok 3, dan kelompok 4 berhasil membuat piggy bank kreatif berbentuk kura-kura dan burung hantu, sedangkan kelompok 2 berhasil membuat piggy bank berbentuk kura-kura, burung hantu, dan pesawat.

Setiap kelompok dapat membuat piggy bank kreatif tersebut dengan bahan yang sangat mudah didapatkan dengan proses pembuatan yang tidak membutuhkan waktu lama, serta hasil yang memuaskan. Hasil penyuluhan, demonstrasi, keseriusan dan antusiasme peserta merupakan modal utama suksesnya kegiatan ini. Tim pelaksana PKM berharap agar peserta dapat menerapkan pengetahun dan keterampilan yang telah diperoleh dari kegiatan PKM ini di dalam kehidupan sehari-hari.

\section{SIMPULAN}

Hasil dari kegiatan pengabdian kepada masyarakat ini antara lain;

1. Peserta memahami tentang; a) manfaat mendaur ulang sampah botol bekas, b) berbagai jenis produk yang dapat dihasilkan dengan mendaur ulang sampah botol bekas, c) manfaat menabung sejak dini bagi masa depan, dan d) cara menabung secara konsisten.

2. Peserta memiliki keterampilan dalam mendaur ulang botol bekas menjadi piggy bank unik dan kreatif. Beberapa produk piggy bank yang dihasilkan siswa antara 
lain; piggy bank berbentuk kura-kura, burung hantu, dan pesawat. Dengan hasil ini, siswa diharapkan dapat lebih termotivasi untuk menabung sejak usia dini.

\section{UCAPAN TERIMA KASIH}

Ucapan terima kasih disampaikan kepada PPLP-PT IKIP PGRI Bojonegoro yang telah mendanai kegiatan pengabdian kepada masyarakat ini dalam bentuk Hibah. Terima kasih juga disampaikan kepada Ketua LPPM IKIP PGRI Bojonegoro, Dekan FPBS, Ketua Program Studi Pendidikan Bahasa Inggris, dan semua pihak yang telah membantu dan mendukung pelaksanaan kegiatan ini sehingga PKM dapat berjalan sukses.

\section{DAFTAR RUJUKAN}

Sumbodo, B. A. R., Dharmawan, A., \& Faizah. (2017). Implementasi Teknologi Internet sebagai Solusi Pengentasan Masalah Komunikasi di Desa Nyamuk, Kecamatan Karimun Jawa, Kabupaten Jepara. Indonesian Journal of Community Engagement, Vol. 2, No. 2, 189-203.

Bagus, Trisaksono. (2002). Pengelolaan dan Pemanfaatan Sampah Menggunakan Teknologi Incenerator. Jurnal Teknologi Lingkungan, Vol. 3, No. 1. 17-23. 